\title{
MAINTAINABILITY FUZZY EVALUATION BASED ON MAINTENANCE TASK VIRTUAL SIMULATION FOR AIRCRAFT SYSTEM
}

\section{OCENA OBSŁUGIWALNOŚCI OPARTA NA TEORII ZBIORÓW ROZMYTYCH BAZUJĄCA NA WIRTUALNEJ SYMULACJI ZADAŃ KONSERWACYJNYCH SYSTEMÓW SAMOLOTU}

\begin{abstract}
Maintainability is a significant design characteristic of civil aircraft system that has great effect on system availability, life cycle cost and operation safety. A virtual maintenance environment is constructed to support maintainability concurrent design of aircraft system, the evaluation method of maintainability attribute is proposed based on maintenance task virtual simulation or maintainability checklist, and then system maintainability comprehensive evaluation is proposed based on fuzzy theory. A case study, which is maintainability evaluation of a nose landing gear system in civil aircraft, shows the effectiveness of the method presented herein.
\end{abstract}

Keywords: maintainability evaluation, virtual simulation, fuzzy theory, aircraft system.

\begin{abstract}
Obshugiwalność jest ważna cecha konstrukcyjna systemów stosowanych w samolotach cywilnych, która ma ogromny wptyw na gotowość systemu, koszty eksploatacji i bezpieczeństwo pracy $W$ przedstawionych badaniach stworzono wirtualne środowisko eksploatacji wspierajace latwość obstugi systemów lotniczych; zaproponowana metoda oceny atrybutu obstugiwalności oparta jest o wirtualna symulację zadań konserwacyjnych lub listę kontrolną obshugiwalności. Następnie zaproponowano kompleksowa ocenę obstugiwalności systemu oparta o teorię zbiorów rozmytych. Studium przypadku, analizujące obstugiwalność systemu podwozia części nosowej cywilnego samolotu, pokazuje skuteczność metody przedstawionej w niniejszym artykule.
\end{abstract}

Slowa kluczowe: ocena obshugiwalności, symulacja wirtualna, teoria zbiorów rozmytych, systemy samolotu.

\section{Introduction}

Maintainability is a significant design characteristic of civil aircraft system, and it has great effects on daily utilization rate, dispatch reliability, life cycle cost and even operation safety of civil aircraft. Maintainability evaluation is an important design task prescribed in MIL-STD-470B [11]. The purpose of maintainability evaluation is to determine whether the specified maintainability requirements of system can be achieved.

According to MIL-STD-471A [12], the traditional maintainability evaluation is conducted by demonstrating maintenance tasks based on physical prototype in the late phase of system development, which has two types of disadvantages: first, evaluated objects are quantitatively parameters such as MTTR (Mean Time To Repair), MTTRS (Mean Time To Restore System) and MTTS (Mean Time To Service), and qualitative requirements related to maintainability design attributes cannot be evaluated in most situation, thus the evaluation conclusion can hardly provide suggestion about design modification; second, maintenance task demonstration is based on physical prototype or real system, even if design deficiencies are found by evaluation, it is difficult to implement design modification because of cost and time. In a word, the traditional maintainability evaluation lags behind the system development and cannot support the concurrent design of modern aircraft system.

In order to solve the above mentioned problems, many literatures have studied in the field. Wani et al. studied the maintainability factors and attributes in product design and developed a procedure based on a digraph and matrix method for evaluation of maintainability in- dex of mechanical systems [21-22]. Meier et al. presented a model process for implementing maintainability and described the potential roles and benefits of maintainability on various types of projects [9]. Pistikopoulos et al. introduced a system effectiveness optimization framework to properly account for maintainability characteristics at the process design level. In the framework, the problem is formulated as a mixed integer linear programming model whose applicability is demonstrated by a numerical example [15]. Chen et al. discussed and identified a set of maintainability factors in terms of physical design, logistics support and ergonomics; and then, as a specific application of design review, a methodology called Vector Projection Method is applied to evaluate the maintainability of the mechanical system [2]. Tjiparuro et al. consolidated maintainability elements and attributes by reconciling and developing previous research efforts and then proposed an approach to maintainability analysis during conceptual design based on the concept of functional design and maintainability axioms [19]. Slavila et al. presented a maintainability evaluation approach based on fuzzy logic; and fuzzy linguistic variables are employed in order to represent and handle the design data available early in the design process [17]. Li et al. analyzed the tribo-maintainability related design factors from systematic perspective and concluded a more complete set of six factors, and then a fuzzy set based approach was developed to quantitatively evaluate maintainability design as well [6]. Desai et al. presented a systematic methodology of design for maintenance to enhance the maintenance operation of products and systems, human factors are also considered in the methodology [3]. Pedro et al. describe a procedure to obtain maintainability indicators 
for industrial devices, they discussed the information obtained through the maintainability assessment process and its computation into several maintainability indicators [13]. ZHOU et al. divided repair time into common and individual repair time, and then proposed a new time characteristics-based maintainability allocation method, which is also applicable to maintainability evaluation [24]. With the development of computer science, virtual reality and digital technology are also used in maintainability analysis and design. Vujosevic proposed the concept of maintainability concurrent design firstly, he presented a computer-aided engineering environment to support maintainability analysis for concurrent design of mechanical system design [20]. Hao et al. developed a maintainability analysis visualization system under the AutoCAD environment, and designers can review their design from the viewpoint of easy maintenance concurrently [5]. Marcelino et al. discussed the design and implementation of a geometric constraint manager that has been designed to support physical realism and interactive assembly and disassembly tasks within virtual environments [7]. Borro et al. developed and integrated a haptic device, which can provide an enhanced sense of real manipulation and can reduce new aircraft engine development costs when conducting maintainability design [1]. Rim et al. proposed a new framework for the evaluation of working conditions by ergonomic and biomechanical analysis using digital models based on XML standard schema, including: products, processes, manufacturing resources and human workers [16]. Peng et al. designed an integrated platform for maintainability design and verification, a case based reasoning method of maintainability design and Extensible Markup Language based representation of maintenance procedure information are presented and used in the platform [14]. Yu et al. provided a fuzzy comprehensive evaluation method for product maintainability evaluation in virtual environment as well. In their research, fuzzy comprehensive evaluation method is used to evaluate product maintainability in virtual maintenance environment at stage of early design [23].

To some extent, the problems of traditional maintainability evaluation have been solved by the above mentioned researches; however, two types of shortages still exist: the one is that the evaluating methods of single maintainability design attribute have not been given, and the other is that maintainability comprehensive evaluation didn't consider detailed maintenance tasks. In order to discover the deficiencies of maintainability design for civil aircraft in the early phase of design, virtual maintenance environment has been constructed in the paper, evaluating methods of maintainability attributes are presented based on virtual demonstration in the virtual maintenance environment, and maintainability comprehensive method is proposed based on fuzzy theory. In this way, the maintainability evaluation can be conducted in the early stage of design, and the concurrent design of maintainability for aircraft system can be realized.

\section{The structure of virtual maintenance environment}

Virtual maintenance environment is a platform for conducting maintenance task virtual demonstration. Our virtual maintenance environment is built based on the Human Task Simulation Solution of software DELMIA developed by Dassault Systemes, in which digital mockup of civil aircraft system, digital maintenance tools and digital human model are integrated.

In order to realize the virtual simulation of maintenance task more conveniently, we have developed standard tool base and human posture base with DELMIA, from which we can generate maintenance tools with different size and kinds of human posture very quickly. In terms of maintenance task virtual simulation, designers can conduct accessibility and ergonomics virtual evaluation for each maintenance task. Fig. 1 shows the architecture of the virtual maintenance environment.

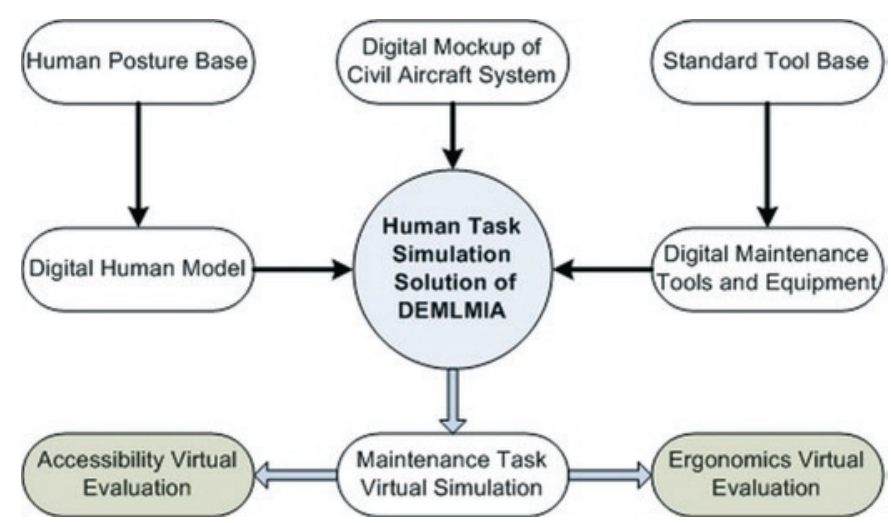

Fig. 1. Architecture of the virtual maintenance environment

\section{Evaluation Methods of maintainability design at- tribute}

The factors affecting product maintainability exist in many aspects including design, maintenance personnel, logistic support, operation context, and so on. In design phase, design factors are the main aspect, maintenance personnel and logistic factors also should be considered; and operation context such as aircraft maintenance manual and illustrated part catalog, which are commonly published after design finished, usually needn't to be considered. So, in design phase, we think that the attributes affecting maintainability of civil aircraft system including accessibility, ergonomics, simplicity, modularization, standardization, identification and testability.

Among all of the seven attributes, accessibility and ergonomics are attributes belonging to each maintenance task of the system, and we think that these attributes must be evaluated according to detailed maintenance task simulation. In another word, to these attributes, system value is the function of its all maintenance tasks' values.

In maintainability engineering, system maintenance is composed of several maintenance events, maintenance event is composed of several maintenance tasks, and each maintenance event is generally corresponding to each replaceable unit. With reference to the relationship between system MTTR and MTTR of each maintenance event [10], the system value of these attributes can be expressed as:

$$
V=\sum_{i=1}^{p} \lambda_{i} V_{i} / \sum_{i=1}^{p} \lambda_{i}
$$

where, $V$ is the system value of these attributes, $V_{i}$ is the $i$ th maintenance event value of these attributes, which is corresponding to the $i$ th replaceable unit of the system, $\lambda_{i}$ is the failure rate of the $i$ th replaceable unit, and $p$ is the number of replaceable unit contained in the system. As the basic evaluation element of these attribute is maintenance task, the relationship between attribute value of maintenance event and its maintenance tasks also should be given, it can be expressed as:

$$
V_{i}=\sum_{j=1}^{q_{i}} t_{i j} V_{i j} / \sum_{j=1}^{q_{i}} t_{i j}
$$

where, $V_{i j}$ is attribute value of the $j$ th maintenance task in the $i$ th maintenance event, $t_{i j}$ is the time of corresponding maintenance task, $q_{i}$ is the number of maintenance tasks in the $i$ th maintenance event. Based on equation (1) and (2), we can calculate the system value of these attributes in terms of their value of maintenance tasks.

Other attributes including simplicity, modularization, standardization, identification and testability are attributes of the whole system or 
product, to these attributes, we will present evaluation method based maintainability checklist in DOD-HDBK-791AM [4].

\subsection{Accessibility and ergonomics evaluation based on main- tenance task simulation}

In DOD-HDBK-791AM [4], accessibility is defined as a design feature that affects the ease of admission to an area for the performance of visual and manipulative maintenance. According to this definition, to each maintenance task, the accessibility contains two aspects, which are visual accessibility and reachable accessibility. In the following section, we will discuss the evaluation method of the both accessibility for each maintenance task.

\section{1) Visual accessibility evaluation}

Visual accessibility of maintenance task shows whether the maintenance personnel can see the corresponding component clearly. The horizontal range of human eyes is 120 degree, and the vertical is 70 degree. Fig. 2 shows the visible range of human eyes, which is provided by visual analysis tool of DELMIA.

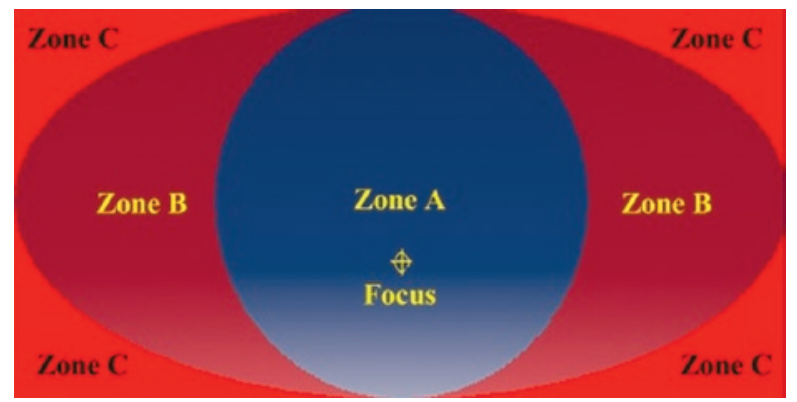

Fig. 2. Visible range of human eyes based on DELMIA

In Fig.2, the range of human vision is divided into three zones, which are zone A, B and C. Zone A's horizontal range is -35 to 35 degrees, zone B's is 35 to 60 degrees or -60 to -35 degrees, and zone $\mathrm{C}$ 's is greater than 60 degrees or less than -60 degree; the vertical range of both zone A and B is -40 to 40 degrees, and zone C's vertical range is less than -40 degrees or 40 degrees. Fig. 3 illustrates the horizontal and vertical range of human vision related to Fig.3.

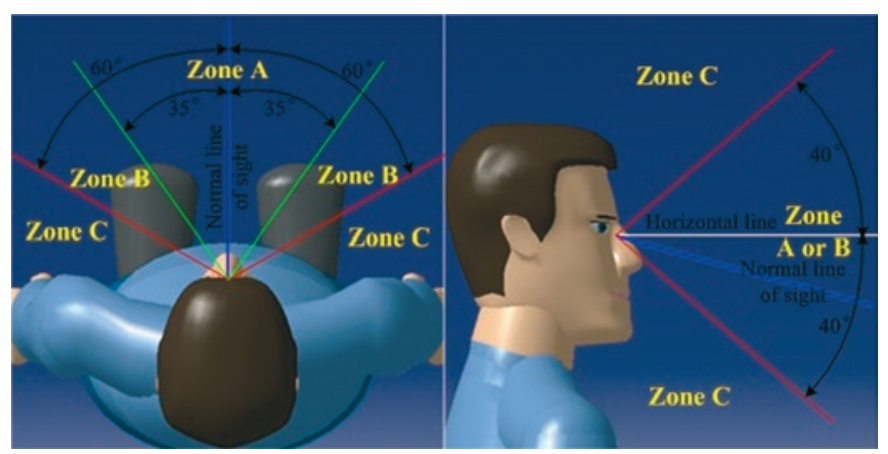

Fig. 3. The horizontal and vertical range of human eyes

We choose typical posture of each maintenance task to conduct visual accessibility evaluation, the attribute values of visual accessibility are expressed by linguistic variable herein, and the values are classified into seven ranks, which are "very satisfied", "satisfied", "a little dissatisfied", "medium", "a little dissatisfied", "dissatisfied" and "very dissatisfied". The evaluation method of visual accessibility is given in Table 1.

\section{2) Reachable accessibility evaluation}

The reachable accessibility of each maintenance task is affected by access doors or covers, tools of maintenance and interference of neighboured components. We also take linguistic variable to express the value of reachable accessibility herein. The evaluation method of reachable accessibility is given in Table 2 .

In Table 2, special tools are in contrast with standard tools such as spanner, screwdriver, wrenches and pliers, most of which are contained in the standard tool base. According to Table 2, we can make evaluation of each maintenance task based on maintenance task simulation.

\section{3) Ergonomics evaluation based on RULA}

The RULA system was developed at the University of Nottingham's Institute for Occupational Ergonomics. It was developed to investigate the exposure of individual workers to risks associated with work-related upper limb disorders. We will use the RULA analysis dialog box of DELMIA to evaluate ergonomics of each maintenance task.

In RULA analysis, risk factors such as number of movements, static muscle work, force, working posture, and time worked without a break are considered to provide a final score that ranges from 1 to 7 .

- 1 and 2 indicate that the posture is acceptable if it is not maintained or repeated for long periods of time;

- 3 and 4 Indicate that further investigation is needed and changes may be required;

- 5 and 6 indicate that investigation and changes are required soon;

- 7 indicates that investigation and changes are required immediately.

Determination of score value is detailed described in Dr. Lynn Mc Atamney and Professor E. Nigel Corlett's work [8]. In order to keep the ergonomics value consistent with accessibility value, we still use linguistic variable to denote RULA score; the linguistic variable "very satisfied", "satisfied", "a little dissatisfied", "medium", "a little dissatisfied", "dissatisfied" and "very dissatisfied" denote RULA score 1 to 7 respectively.

Fig. 4 is an illustration instance of using RULA analysis dialog box in DELMIA to evaluate ergonomics of the maintenance task installing wheel in NLG of civil aircraft.

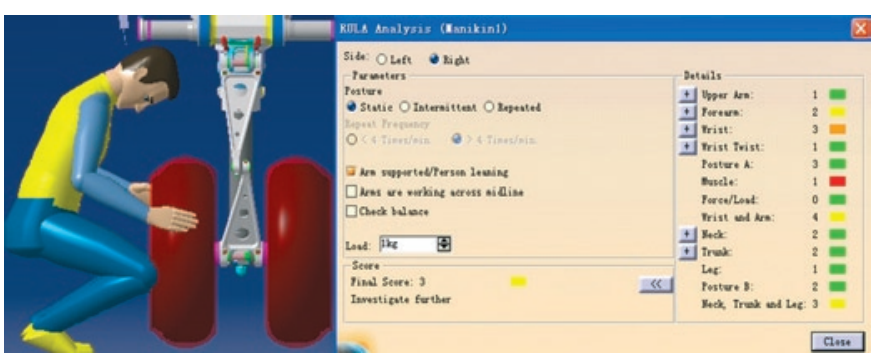

Fig. 4. RULA instance of wheel disassembly

\section{4) Normalization of linguistic variable}

In the previous context, the attribute value is expressed by linguistic variable, which can't be calculated by Equation (1) and (2) directly, as it is not numerical and has not been normalized. We use triangular fuzzy number to represent linguistic variables. Triangular fuzzy number is denoted as $\left(v^{l}, v^{m}, v^{u}\right)$, where $0 \leq v^{l} \leq v^{m} \leq v^{u} \leq 1, v^{m}$ is the most possible value of a linguistic variable or RULA score, $v^{l}$ is the lower bound and $v^{u}$ is the upper bound. The operation rules of triangular fuzzy number are given in Equation (3).

$$
\begin{aligned}
& \left(v_{i}^{l}, v_{i}^{m}, v_{i}^{u}\right) \pm\left(v_{j}^{l}, v_{j}^{m}, v_{j}^{u}\right)=\left(v_{i}^{l}+v_{j}^{l}, v_{i}^{m}+v_{j}^{m}, v_{i}^{u}+v_{j}^{u}\right) \\
& k \times\left(v^{l}, v^{m}, v^{u}\right)=\left(k v^{l}, k v^{m}, k v^{u}\right) \\
& \left(v^{l}, v^{m}, v^{u}\right) / k=\left(v^{l} / k, v^{m} / k, v^{u} / k\right)
\end{aligned}
$$


Table 1. Evaluation rule of visual accessibility

\begin{tabular}{|c|c|}
\hline Attribute Value & Rules of Judgement \\
\hline very satisfied & $\begin{array}{l}\text { In the typical posture, the component to be dismantled or installed locates in zone A and the geometric centre of the component is } \\
\text { the focus. }\end{array}$ \\
\hline satisfied & In the typical posture, the component to be dismantled or installed locates in zone A but the geometric centre is not the focus. \\
\hline a little satisfied & In the typical posture, the component to be dismantled or installed locates in zone A and B, and the geometric centre is in zone A. \\
\hline medium & $\begin{array}{l}\text { In the typical posture, the component to be dismantled or installed locates in zone A and B, and the geometric centre is in the bor- } \\
\text { der between zone A and B. }\end{array}$ \\
\hline a little dissatisfied & In the typical posture, the component to be dismantled or installed locates in zone A and B, and the geometric centre is in zone B. \\
\hline dissatisfied & $\begin{array}{l}\text { In the typical posture, most part of the component to be dismantled or installed locates in zone B, and the geometric centre is in } \\
\text { zone B. }\end{array}$ \\
\hline very dissatisfied & In the typical posture, most part of the component to be dismantled or installed locates in zone C. \\
\hline
\end{tabular}

Table 2. Evaluation rule of reachable accessibility

\begin{tabular}{|c|c|}
\hline Attribute Value & Rules of Judgement \\
\hline very satisfied & $\begin{array}{l}\text { The maintenance task can be finished without opening access doors, without special tools, and the task is not interfered by neigh- } \\
\text { boured components. }\end{array}$ \\
\hline satisfied & $\begin{array}{l}\text { The maintenance task must be finished with opening access doors or with special tools, but the task is not interfered by neigh- } \\
\text { boured components. }\end{array}$ \\
\hline a little satisfied & $\begin{array}{l}\text { The maintenance task must be finished with opening access doors and with special tools, but the task is not interfered by neigh- } \\
\text { boured components. }\end{array}$ \\
\hline medium & $\begin{array}{l}\text { The maintenance task can be finished without opening access doors and without special tools, but the task is interfered by neigh- } \\
\text { boured components slightly. }\end{array}$ \\
\hline a little dissatisfied & $\begin{array}{l}\text { The maintenance task must be finished either with opening access doors and special tools, and the task is interfered by neigh- } \\
\text { boured components slightly. }\end{array}$ \\
\hline dissatisfied & The maintenance task is interfered by neighboured components severely. \\
\hline very dissatisfied & The maintenance task cannot be finished because of interference of neighboured components. \\
\hline
\end{tabular}

Triangular fuzzy number can reflect the fuzziness of linguistic variable; Fig. 5 shows the memberships of each linguistic variable that are "very satisfied", "satisfied", "a little dissatisfied", "medium", "a little dissatisfied", "dissatisfied" and "very dissatisfied".

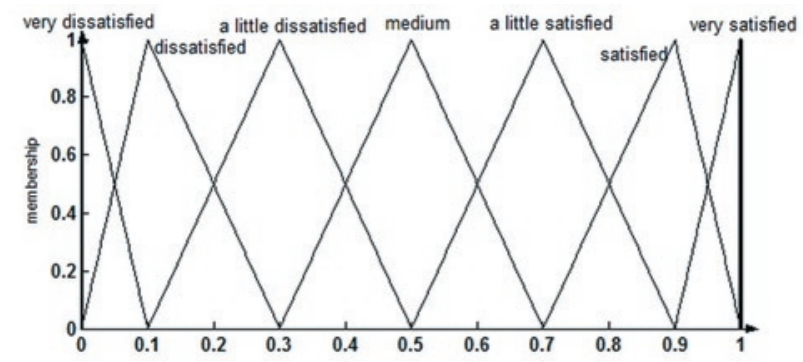

Fig. 5. Membership functions of linguistic variables

According to the membership function, we can get the triangular fuzzy number corresponding to each linguistic variable, which is shown in Table 3.

\section{Table 3. Triangular fuzzy number of each linguistic variable}

\begin{tabular}{cc}
\hline \hline Linguistic variable & Triangular fuzzy number \\
\hline Very dissatisfied & $(0,0,0.1)$ \\
Dissatisfied & $(0,0.1,0.3)$ \\
A little dissatisfied & $(0.1,0.3,0.5)$ \\
Medium & $(0.3,0.5,0.7)$ \\
A little satisfied & $(0.5,0.7,0.9)$ \\
Satisfied & $(0.7,0.9,1)$ \\
Very satisfied & $(0.9,1,1)$ \\
\hline \hline
\end{tabular}

\subsection{Evaluation of other attributes based on maintainability checklist}

Except for accessibility and ergonomics, other attributes are evaluated based on checklist in our paper. In DOD-HDBK-791AM [4], maintainability checklists are proposed for all these attributes, the evaluation process of each attribute based on maintainability checklist is given step by step as following:

a) To tailor the maintainability checklist in DOD-HDBK-791AM [4], since maintainability checklist in the file is a general one, we must choose the proper items from the checklist according to our researching object;

b) To judge whether the design of our researching object can satisfy the requirement of each item in the tailored maintainability checklist;

c) To calculate the numerical attribute value, which can be acquired by equation (4):

$$
V=f\left(n_{s} / n_{a}\right)
$$

where, $V$ is the numerical value of the attribute; $n_{a}$ is the number of all items contained in tailored maintainability checklist; $n_{s}$ is the number of items that our researching object satisfied; $f(\bullet)$ is the effectiveness function, which describes the relationship between $n_{s} / n_{a}$ and $V$.

To simplicity, modularization, standardization and testability, we think the result will be "medium" if about $70 \%$ items in the tailored checklist are satisfied, and therefore, the effectiveness function of these attributes is expressed as:

$$
f\left(n_{s} / n_{a}\right)=\left(n_{s} / n_{a}\right)^{2}
$$


To Identification, as it will affect system safety, all items in the tailored checklist must be satisfied, or else, the result can't be accepted; thus, the effectiveness function of identification is expressed as:

$$
f\left(n_{s} / n_{a}\right)= \begin{cases}1 & n_{s} / n_{a}=1 \\ 0 & \text { otherwise }\end{cases}
$$

d) To convert the numerical attribute value to Triangular fuzzy number.

To keep the evaluation value consistent with accessibility and ergonomics, we should convert the numerical value to triangular fuzzy number.

The linguistic variable set $Y=\left\{y_{1}, y_{2}, y_{3}, y_{4}, y_{5}, y_{6}, y_{7}\right\}$ is also chosen as evaluation set, where $y_{1}$ to $y_{7}$ denote linguistic variable "very dissatisfied" to "very satisfied". The membership function of each linguistic variable shown in Fig. 5 can be expressed as:

$$
\begin{aligned}
& y_{1}(x)=\left\{\begin{array}{cc}
-10 x+1 & 0 \leq x<0.1 \\
0 & \text { otherwise }
\end{array}\right. \\
& y_{2}(x)=\left\{\begin{array}{cc}
10 x & 0 \leq x<0.1 \\
-5 \mathrm{x}+1.5 & 0.1 \leq x<0.3 \\
0 & \text { otherwise }
\end{array}\right. \\
& y_{3}(x)=\left\{\begin{array}{cc}
5 x-0.5 & 0.1 \leq x<0.3 \\
-5 \mathrm{x}+2.5 & 0.3 \leq x<0.5 \\
0 & \text { otherwise }
\end{array}\right. \\
& y_{4}(x)=\left\{\begin{array}{cc}
5 x-1.5 & 0.3 \leq x<0.5 \\
-5 \mathrm{x}+3.5 & 0.5 \leq x<0.7 \\
0 & \text { otherwise }
\end{array}\right. \\
& y_{5}(x)=\left\{\begin{array}{cc}
5 x-2.5 & 0.5 \leq x<0.7 \\
-5 \mathrm{x}+4.5 & 0.7 \leq x<0.9 \\
0 & \text { otherwise }
\end{array}\right. \\
& y_{6}(x)=\left\{\begin{array}{cc}
5 x-3.5 & 0.7 \leq x<0.9 \\
-10 \mathrm{x}+10 & 0.9 \leq x<1 \\
0 & \text { otherwise }
\end{array}\right. \\
& y_{7}(x)=\left\{\begin{array}{cc}
10 x-9 & 0.9 \leq x \leq 1 \\
0 & \text { otherwise }
\end{array}\right.
\end{aligned}
$$

The conversion equation can be expressed as:

$$
\left(v^{l}, v^{m}, v^{u}\right)=\sum_{i=1}^{7} y_{i}(f(\bullet)) \times\left(v_{i}^{l}, v_{i}^{m}, v_{i}^{u}\right)
$$

where, $y_{i}$ is the membership function of the $i$ th linguistic variable, $\left(v_{i}^{l}, v_{i}^{m}, v_{i}^{u}\right)$ is the triangular fuzzy number of the ith linguistic variable.

\section{System maintainability fuzzy evaluation}

If each maintainability attribute value is better than "medium", we think the result is acceptable, and then we can conduct comprehensive evaluation of system maintainability, otherwise, the design must be modified. We propose a comprehensive evaluation method of system maintainability based on fuzzy weighted sum.

\subsection{Weight calculation}

AHP method [18, 23] is used to determine weights of the eight maintainability attributes, which are shown in Fig. 6.

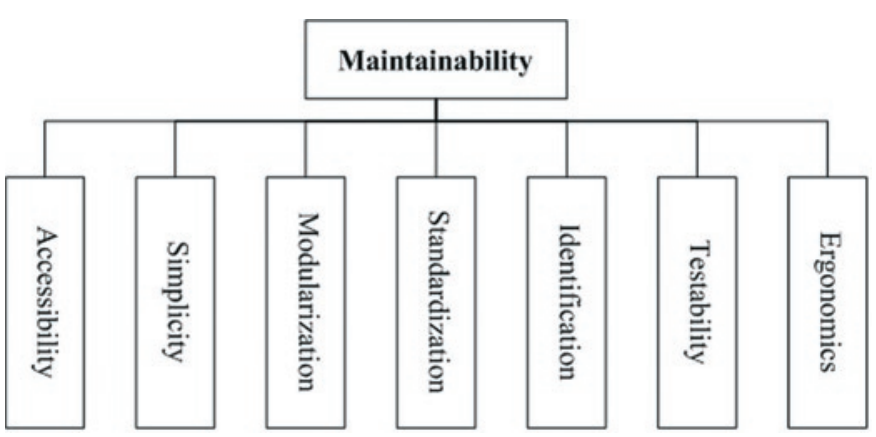

Fig. 6 Maintainability attributes of aircraft system

In AHP method weight of each attribute is acquired by pair-wise comparison matrix $\mathrm{C}$, which is expressed as:

$$
C=\left[c_{i j}\right]=\left[\begin{array}{cccc}
1 & c_{12} & \cdots & c_{18} \\
c_{21} & 1 & \cdots & c_{28} \\
\vdots & \vdots & \vdots & \vdots \\
w_{n} / w_{1} & w_{n} / w_{2} & \cdots & 1
\end{array}\right]
$$

where, $c_{i j}$ denotes the relative importance bewteen attribute $i$ and $j$ ( $i$, $j=1$ to 8 ) given by experienced designers; the value of $c_{i j}$ has 9 levels shown in table 4 , and $c_{i j}$ is the reciprocal of $c_{j i}$.

Table 4. The assessment rule of relative importance

\begin{tabular}{cc}
\hline \hline Value of $c i j$ & Preference of attribute $i$ to $j$ \\
\hline 1 & Equally preferred \\
3 & Moderately preferred \\
5 & Strongly preferred \\
7 & Very strongly preferred \\
9 & Extremely preferred \\
$2,4,6,8$ & Intermediate levels \\
\hline \hline
\end{tabular}

The weights vector $W=\left[w_{1}, w_{2}, w_{3}, w_{4}, w_{5}, w_{6}, w_{7}, w_{8}\right]$ is the unitary eigenvector corresponding to the principal eigenvalue $\lambda_{\max }$ of the pair-wise comparison matrix $C$. To ensure the consistency of pairwise comparison matrix, the consistency is evaluated by consistency ratio $C R$ :

$$
C R=\frac{\lambda_{\max }-n}{(n-1) \times R I(n)}
$$

where, $R I(n)$ is the random consistency index. If $C R$ is not greater than 0.1 , the consistency will be accepted.

\subsection{Calculation of system maintainability value}

The system maintainability value is also denoted by fuzzy triangular number, which is expressed as:

$$
\left(v_{s}^{l}, v_{s}^{m}, v_{s}^{u}\right)=\sum_{i=1}^{8} w_{q} \times\left(v_{q}^{l}, v_{q}^{m}, v_{q}^{u}\right)
$$

where, $\left(v_{s}^{l}, v_{s}^{m}, v_{s}^{u}\right)$ is the value of system maintainability, $\left(v_{q}^{l}, v_{q}^{m}, v_{q}^{u}\right)$ is the value of the $q$ th maintainability attribute, and $w_{i}$ is the weight of the qth maintainability attribute. 


\section{Case study}

\subsection{Case study of evaluation based on maintenance task virtual demonstration}

An example of a NLG system is used to illustrate our approach of accessibility and ergonomics evaluation. The NLG system consists of one shock strut, one drag strut, one lock stay, one Retraction actuator, one lock actuator, two down lock springs, two wheels and four door links, therefore, the maintenance events of the system are replacement of these LRUs. Take wheel replacement as an example, the maintenance event consists of eight maintenance tasks, which are removing cotter pins, removing bolts and nuts, removing wheel fastener, removing wheel, installing a new wheel, installing wheel fastener, installing the bolts and nuts, installing new cotter pins. The virtual simulation of these maintenance tasks is shown in Fig. 7.

Based on the maintenance task virtual simulation and evaluation methods mentioned above, we can determine that the visual accessibility values of all tasks are "satisfied" or "very satisfied". As Fig. 7(b) shown, bolt and nut removing or installing are interfered by wheel rim
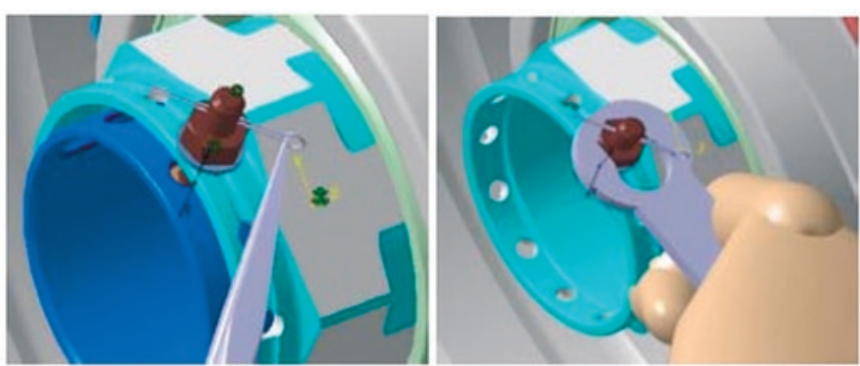

(a) removing cotter pin

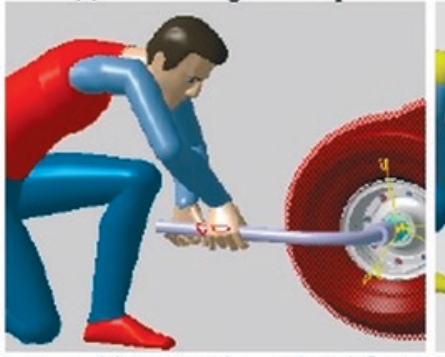

(b) removing bolt and nut

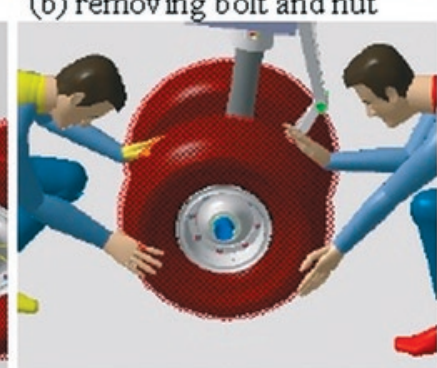

(c) removing wheel fastener (d) removing wheel

Fig. 7. Maintenance task virtual demonstration of wheel replacement

Table 5. Attribute values of each maintenance task in wheel replacement

\begin{tabular}{|c|c|c|c|c|c|c|}
\hline $\begin{array}{c}\text { Maintenance } \\
\text { event }\end{array}$ & Maintenance task & $\begin{array}{l}\text { Number of } \\
\text { the task }\end{array}$ & Time of the task & $\begin{array}{c}\text { Visual accessibility } \\
\text { value }\end{array}$ & $\begin{array}{c}\text { Reachable accessibility } \\
\text { value }\end{array}$ & Ergonomics value \\
\hline \multirow{8}{*}{$\begin{array}{l}\text { Replace of } \\
\text { wheel }\end{array}$} & Removing cotter pin & 8 & $0.4 \mathrm{~min}$ & $\begin{array}{l}\text { Very satisfied } \\
\quad(0.9,1,1)\end{array}$ & $\begin{array}{c}\text { Very satisfied } \\
(0.9,1,1)\end{array}$ & $\begin{array}{l}\text { A little satisfied } \\
(0.5,0.7,0.9)\end{array}$ \\
\hline & Removing bolt and nut & 8 & $0.6 \mathrm{~min}$ & $\begin{array}{c}\text { Very satisfied } \\
(0.9,1,1)\end{array}$ & $\begin{array}{l}\text { Medium } \\
(0.3,0.5,0.7)\end{array}$ & $\begin{array}{l}\text { A little satisfied } \\
(0.5,0.7,0.9)\end{array}$ \\
\hline & Removing wheel fastener & 1 & $2.5 \mathrm{~min}$ & $\begin{array}{l}\text { Satisfied } \\
(0.7,0.9,1)\end{array}$ & $\begin{array}{l}\text { Satisfied } \\
(0.7,0.9,1)\end{array}$ & $\begin{array}{l}\text { Medium } \\
(0.3,0.5,0.7)\end{array}$ \\
\hline & Removing wheel & 1 & $2.5 \mathrm{~min}$ & $\begin{array}{l}\text { Satisfied } \\
(0.7,0.9,1)\end{array}$ & $\begin{array}{c}\text { Very satisfied } \\
(0.9,1,1)\end{array}$ & $\begin{array}{l}\text { Medium } \\
(0.3,0.5,0.7)\end{array}$ \\
\hline & Installing a new wheel & 1 & $3 \mathrm{~min}$ & $\begin{array}{l}\text { Satisfied } \\
(0.7,0.9,1)\end{array}$ & $\begin{array}{l}\text { Very satisfied } \\
\quad(0.9,1,1)\end{array}$ & $\begin{array}{l}\text { Medium } \\
(0.3,0.5,0.7)\end{array}$ \\
\hline & $\begin{array}{l}\text { Installing the wheel fas- } \\
\text { tener }\end{array}$ & 1 & $3 \min$ & $\begin{array}{l}\text { Satisfied } \\
(0.7,0.9,1)\end{array}$ & $\begin{array}{l}\text { Satisfied } \\
(0.7,0.9,1)\end{array}$ & $\begin{array}{l}\text { Medium } \\
(0.3,0.5,0.7)\end{array}$ \\
\hline & Installing the bolt and nut & 8 & $0.8 \mathrm{~min}$ & $\begin{array}{c}\text { Very satisfied } \\
(0.9,1,1)\end{array}$ & $\begin{array}{l}\text { Medium } \\
(0.3,0.5,0.7)\end{array}$ & $\begin{array}{l}\text { A little satisfied } \\
(0.5,0.7,0.9)\end{array}$ \\
\hline & Installing new cotter pin & 8 & $0.5 \mathrm{~min}$ & $\begin{array}{c}\text { Very satisfied } \\
(0.9,1,1)\end{array}$ & $\begin{array}{c}\text { Very satisfied } \\
(0.9,1,1)\end{array}$ & $\begin{array}{c}\text { A little satisfied } \\
(0.5,0.7,0.9)\end{array}$ \\
\hline
\end{tabular}

slightly, thus, their reachable accessibility values are "medium"; and as Fig. 7(c) shown, wheel fastener removing or installing need high torque impact wrench that is a special tool, thus, reachable accessibility values of these tasks are "satisfied" not "very satisfied". Table 5 shows the three attribute values of each maintenance task.

According to equation (2) and equation (3), we can get the three attribute values of the maintenance event "Replace of wheel", the visual accessibility value is $(0.83,0.96,1)$, the Reachable accessibility value is $(0.63,0.79,0.89)$, and the Ergonomics value is $(0.43,0.63,0.83)$.

We give the three attribute values of other maintenance events directly, which are shown in Table 6 . The unit of failure rate is $10^{-6}$ hours.

According to equation (1) equation (3), we can get the three attribute values of the NLG system, the visual accessibility value is $(0.80,0.94,1)$, the Reachable accessibility value is $(0.61,0.77,0.89)$, and the Ergonomics value is $(0.51,0.69,0.88)$.

\subsection{Case study of evaluation based on maintainability checklist}

We assume that the tailored simplicity checklist of our aforementioned NLG system is shown in Table 7.

According to equation (5), we can get the numerical value of simplicity:

$$
V=(8 / 10)^{2}=0.64
$$

Base on equation (7) and (8), we can get the triangular fuzzy number of simplicity:

$\left(v^{l}, v^{m}, v^{u}\right)=0.3 \times(0.3,0.5,0.7)+0.7 \times(0.5,0.7,0.9)=(0.44,0.64,0.84)$

\subsection{Case study of system maintainability fuzzy comprehen- sive evaluation}

We take two types of NLG system as our evaluation object, which are shown in Fig. 8, the left is system A and the right is system B.

System A is just our aforementioned NLG system and most part of system B is similar to system A, the differences exist in two facets:

1) The cabin of NLG system A has four doors that are two front doors and two rear doors, the cabin of system B has only two symmetric doors, thus, system A has four door links and sys- 
Table 6. Attribute values of the NLG's all maintenance events

\begin{tabular}{cccccc}
\hline \hline Maintenance event & $\begin{array}{c}\text { Number of the } \\
\text { LRU }\end{array}$ & $\begin{array}{c}\text { Failure rate of the } \\
\text { LRU }\end{array}$ & Visual accessibility value & $\begin{array}{c}\text { Reachable accessibility } \\
\text { value }\end{array}$ & Ergonomics value \\
\hline Shock strut & 1 & 534 & $(0.74,0.91,1)$ & $(0.52,0.71,0.89)$ & $(0.39,0.55,0.73)$ \\
Drag strut & 1 & 134 & $(0.75,0.89,1)$ & $(0.51,0.69,0.88)$ & $(0.45,0.63,0.81)$ \\
Lock stay & 1 & 167 & $(0.72,0.88,1)$ & $(0.55,0.69,0.84)$ & $(0.83,0.93,1)$ \\
Retraction actuator & 1 & 157 & $(0.82,0.95,1)$ & $(0.45,0.63,0.81)$ & $(0.61,0.72,0.89)$ \\
Lock actuator & 1 & 145 & $(0.79,0.94,1)$ & $(0.39,0.55,0.73)$ & $(0.82,0.95,1)$ \\
Down lock spring & 2 & 33 & $(0.83,0.96,1)$ & $(0.61,0.72,0.89)$ & $(0.65,0.81,0.92)$ \\
Door link & 4 & 211 & $(0.71,0.89,1)$ & $(0.64,0.81,0.92)$ & $(0.83,0.95,1)$ \\
Wheel & 2 & 1894 & $(0.83,0.96,1)$ & $(0.63,0.79,0.89)$ & $(0.43,0.63,0.83)$ \\
\hline \hline
\end{tabular}

Table 7. Tailored simplicity checklist of the NLG system

\begin{tabular}{crc}
\hline \hline Item code & Item & Satisfied? \\
\hline 1 & The system must be searched for simplified alternatives. & Yes \\
2 & The manual data must be understood by an average person with a junior high school education. & No \\
3 & The function must be performed by a standard or existing part. & No \\
4 & Simplification brainstorming must be attempted. & Yes \\
5 & All function or part must be really necessary. & Yes \\
6 & All wrenching or adjustment locations are visible in prevailing light? & Yes \\
7 & The number of attachments must be minimized. & Yes \\
8 & Adjus Table circuits cannot be further reduced. & Yes \\
9 & Mechanical adjustments must be held to a minimum. & Yes \\
10 & Diagnostic techniques must be simplified? & Yes \\
\hline \hline
\end{tabular}

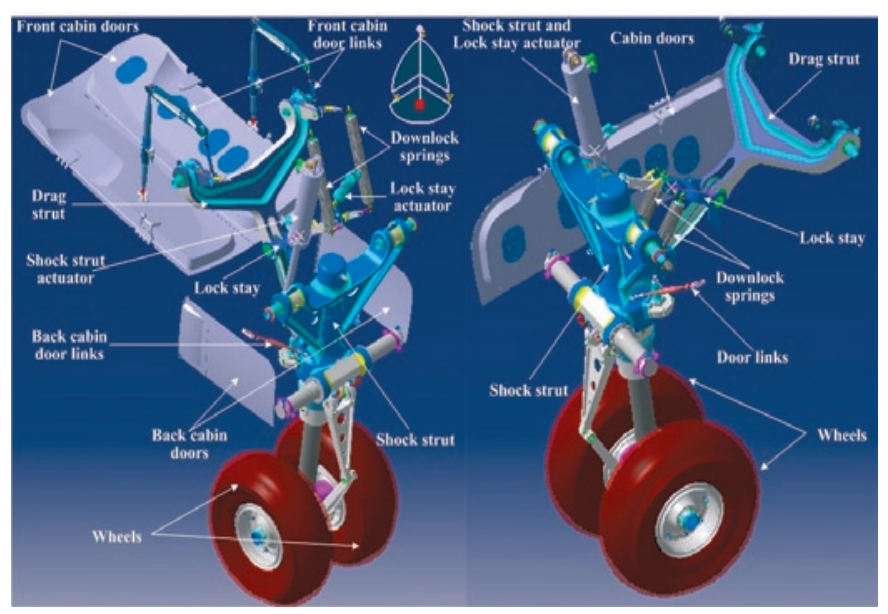

Fig. 8. Two types of NLG system

tem B has two door links. In general, the simplicity of system A is worse than system B, however, the accessibility of system $\mathrm{A}$ is better than system $\mathrm{B}$.

2) The system A has an independent lock actuator to lock the NLG when it is in up position; the system B has only one actuator that has both retraction and lock function, so the modularization of system $\mathrm{B}$ is better than system A.

The evaluation values of each attribute of the two NLG systems are shown in table 8 .

By consulting design experts and maintenance experts, we can get the pair-wise comparison matrix, which is:

$$
C=\left[\begin{array}{cccccccc}
1 & 1 / 2 & 1 & 1 / 3 & 2 & 3 & 1 / 3 & 1 \\
2 & 1 & 2 & 1 & 5 & 5 & 1 & 2 \\
1 & 1 / 2 & 1 & 1 / 2 & 2 & 3 & 1 / 4 & 1 \\
3 & 1 & 2 & 1 & 4 & 5 & 1 & 2 \\
1 / 2 & 1 / 5 & 1 / 2 & 1 / 4 & 1 & 1 & 1 / 7 & 1 / 2 \\
1 / 3 & 1 / 5 & 1 / 3 & 1 / 5 & 1 & 1 & 1 / 6 & 1 / 2 \\
3 & 1 & 4 & 1 & 7 & 6 & 1 & 3 \\
1 & 1 / 2 & 1 & 1 / 2 & 2 & 2 & 1 / 3 & 1
\end{array}\right]
$$

The principal eigenvalue of matrix is $8.078, \quad R I(8)=1.41$, according to equation (10), we can get the consistency ratio $C R=0.0079<0.01$, so the consistency is accepted. And we can get the weight vector for all maintainability attributes based on eigenvector of maximum eigenvalue, which is:

$\boldsymbol{W}=[0.0884,0.1963,0.0900,0.2020,0.0420,0.0378,0.2555,0.0879]$

And then, according to equation (11), we can get the system maintainability values of the two NLG system, which are $(0.6671,0.8010$, $0.9366)$ of the NLG system 1 and $(0.6865,0.8160,0.9420)$ of NLG system 2 . We can know that the maintainability levels of the both NLG systems are between "a little satisfied" to "satisfied", and the maintainability of NLG system A is a little better than system B.

\section{Conclusions}

In the paper, line maintenance of civil aircraft system is taken as research object, virtual maintenance environment has been constructed for aircraft system, evaluating methods are presented based on maintenance task simulation or maintainability checklist for different types of maintainability design attributes, and the maintainability 
Table 8. Evaluation values of each attribute of the two NLG systems

\begin{tabular}{ccccc}
\hline \hline System code & Visual accessibility & Reachable accessibility & Ergonomics & Simplicity \\
\hline A & $(0.80,0.94,1)$ & $(0.63,0.79,0.89)$ & $(0.51,0.69,0.88)$ & $(0.44,0.64,0.84)$ \\
B & $(0.80,0.92,1)$ & $(0.60,0.76,0.86)$ & $(0.52,0.67,0.87)$ & $(0.53,0.73,0.92)$ \\
System code & Modularization & Standardization & Identification & Testability \\
A & $(0.51,0.71,0.90)$ & $(0.70,0.90,1)$ & $(0.9,1,1)$ & $(0.69,0.89,0.99)$ \\
B & $(0.65,0.85,0.97)$ & $(0.70,0.90,1)$ & $(0.9,1,1)$ & $(0.68,0.88,0.99)$ \\
\hline \hline
\end{tabular}

comprehensive method of aircraft system is proposed based on fuzzy theory.

The contribution of the paper is shown in the following three aspects:

1) A virtual maintenance environment, in which maintenance task virtual simulation can be conducted, has been constructed to support maintainability concurrent design of aircraft system. The evaluation method of maintainability attributes, such as visual accessibility, reachable accessibility and ergonomics are presented according to maintenance task virtual simulation; and the maintainability design deficiencis can be discovered in the early design stage.

2) The comprehensive evaluation method of system maintainability is proposed based on fuzzy theory, as our final evaluation result is given in the form of fuzzy triangular number, we can know the absolute system maintainability level when there is only one candidate design scheme, and we also can choose the best one from several candidate design schemes by comparing their final results.

Acknowledgements
The authors wish to appreciate the support from National Natural
Science Foundation of China (61403192) and the Fundamental
Research Funds for the Central Universities of China (NS2011008).

\section{References}

1. Borro D, Savall J, A Amundarain, et al. A large haptic device for aircraft engine maintainability. IEEE Computer Graphics and Applications, 2004, 24(6):70-74, http://dx.doi.org/10.1109/MCG.2004.45.

2. Chen L, Cai J G. Using Vector Projection Method to evaluate maintainability of mechanical system in design review. Reliability Engineering \& System Safety, 2003, 81(2):147-154, http://dx.doi.org/10.1016/S0951-8320(03)00075-9.

3. Desai A, Mital A. Improving maintainability of products through the adoption of a comprehensive design for maintainability method. International Journal of Industrial Engineering-Theory Applications and Practice, 2010, 17(2): 103-114.

4. DOD-HDBK-791AM. Maintainability Design Techniques. U.S. Department of Defense, 1988.

5. Hao J P, Yu Y L, Xue Q. A maintainability analysis visualization system and its development under the AutoCAD environment. Journal of Materials Processing Technology, 2002, 129(1-3): 277-282, http://dx.doi.org/10.1016/S0924-0136(02)00665-9.

6. Li J R, Wang Q H, Shen H Z. Fuzzy evaluation of maintainability with tribological factors at design stage. In Applied Mechanics and Mechanical Engineering, 2010, 20-32: 1027-1033.

7. Marcelino L, Murray N, Fernando T. A constraint manager to support virtual maintainability. Computers \& Graphics-Uk, 2003, 27(1): 19-26, http://dx.doi.org/10.1016/S0097-8493(02)00228-5.

8. McAtamney L, Corlett E N. RULA. A survey method for the investigation of work-related upper limb disorders. Applied Ergonomics, 1993, 24(2): 91-99, http://dx.doi.org/10.1016/0003-6870(93)90080-S.

9. Meier J R, Russell J S. Model process for implementing maintainability. Journal of Construction Engineering and Management-Asce, 2000, 126(6): 440-450, http://dx.doi.org/10.1061/(ASCE)0733-9364(2000)126:6(440).

10. MIL-HDBK-472 Notice 1. Maintainability Prediction. USA Department of Defense. U.S. Department of Defense, 1984.

11. MIL-STD-470B. Maintainability Program Requirements for Systems and Equipment. U.S. Department of Defense, 1989.

12. MIL-STD-471A. Maintainability Verification/ Demonstration/ Evaluation. U.S. Department of Defense, 1973.

13. Pedro M D L,Vicente G P D, Luis B M, et al. A practical method for the maintainability assessment in industrial devices using indicators and specific attributes. Reliability Engineering \& System Safety, 100 (2012): 84-92, http://dx.doi.org/10.1016/j.ress.2011.12.018.

14. Peng G L, Yu H Q, Liu X H, et al. A desktop virtual reality-based integrated system for complex product maintainability design and verification. Assembly Automation, 2010, 30(4): 333-344, http://dx.doi.org/10.1108/01445151011075799.

15. Pistikopoulos E N, Vassiliadis C G, Papageorgiou L G. Process design for maintainability: an optimization approach. Computers \& Chemical Engineering, 2000, 24(2-7): 203-208, http://dx.doi.org/10.1016/S0098-1354(00)00514-7.

16. Rim Y H, Moon J H, Kim G Y, et al. Ergonomic and biomechnical analysis of automotive general assembly using xml and digital human models. International Journal of Automotive Technology, 2008, 9 (6): 719-728, http://dx.doi.org/10.1007/s12239-008-0085-7.

17. Slavila C A, Decreuse C, Ferney M. Fuzzy approach for maintainability evaluation in the design process. Concurrent Engineering-Research and Applications, 2005, 13(4): 291-300, http://dx.doi.org/10.1177/1063293X05059807.

18. Thomas L S. How to make a decision: The analytic hierarchy process. European Journal of Operational Research, 1990, 48(1): 9-26, http:// dx.doi.org/10.1016/0377-2217(90)90057-I.

19. Tjiparuro Z, Thompson G. Review of maintainability design principles and their application to conceptual design. Proceedings of the Institution of Mechanical Engineers Part E-Journal of Process Mechanical Engineering, 2004, 218(E2): 103-113, http://dx.doi. org/10.1243/095440804774134280. 
20. Vujosevic R. Maintainability Analysis in Concurrent Engineering of Mechanical Systems.Concurrent Engineering: Research and Applications, 1995, 3(1): 61-73, http://dx.doi.org/10.1177/1063293X9500300108.

21. Wani M F and O P Gandhi. Development of maintainability index for mechanical systems.Reliability Engineering \& System Safety, 1999, 65(3): 259-270, http://dx.doi.org/10.1016/S0951-8320(99)00004-6.

22. Wani M F and O P Gandhi. Maintainability design and evaluation of mechanical systems based on tribology. Reliability Engineering \& System Safety, 2002, 77(2):181-188, http://dx.doi.org/10.1016/S0951-8320(02)00032-7.

23. Yu H Q, Peng G L, Liu W J. A practical method for measuring product maintainability in a virtual environment. Assembly Automation, 2011, 31(1):53-61, http://dx.doi.org/10.1108/01445151111104173.

24. ZHOU D, JIA X, LV C, et al. Maintainability Allocation Method Based on Time Characteristics for Complex Equipment. Eksploatacja i Niezawodność- Maintenance and Reliability, 2013; 15 (4): 441-448.

\section{Zhong LU}

College of Civil Aviation,

Nanjing University of Aeronautics and Astronautics

29 Jiangjun Road, Nanjing 211106, China

\section{Jia ZHOU}

Department of Aircraft Maintenance

China Eastern Airlines Jiangsu Limited

Nanjing 211113, China

\section{Naixin LI}

College of Civil Aviation,

Nanjing University of Aeronautics and Astronautics

29 Jiangjun Road, Nanjing 211106, China

E-mail: luzhong@nuaa.edu.cn, zhou_jia81@126.com, kogdamer@163.com 